\title{
Application of Cloud Accounting in Comprehensive Budget Management of Agricultural Enterprises under Big Data
}

\author{
Xu Yan ${ }^{1 \mathrm{a}}$ Xiao Nanyun ${ }^{1 \mathrm{~b}}$ \\ ${ }^{1}$ Harbin Finance University Department of Accounting Harbin, Heilongjiang, China
}

\begin{abstract}
Cloud accounting is a new technology developed on the basis of network information technology under the background of big data, which can provide convenient services for accounting and management of enterprises. The development of agricultural enterprises is directly related to the development of local agricultural economy. However, the application of cloud accounting in agricultural enterprises is less, and the application in comprehensive budget management is insufficient, which hinders the efficient docking of agricultural enterprises and economy. Therefore, this study believes that agricultural enterprises can use the advantages of big data and cloud accounting platform to build a more information-based comprehensive budget management system, in order to further improve the core competitiveness of agricultural enterprises.
\end{abstract}

\section{Introduction}

Agricultural enterprises refer to the profitable economic organizations that obtain products through planting, breeding, collecting, fishing and hunting, etc., which play an important role in boosting agricultural economy. In order to better realize scientific strategic planning, agricultural enterprises have entered the stage of comprehensive budget management. Comprehensive budget management can comprehensively reflect the objectives and action plans of agricultural enterprises in various aspects of production and operation activities in a certain period. With the rapid development of computer Internet technology and the background of big data, cloud accounting is increasingly becoming the mainstream application technology. It is necessary and feasible for agricultural enterprises to integrate comprehensive budget management and cloud accounting technology.

\section{The significance of cloud accounting in the comprehensive budget management of agricultural enterprises}

\subsection{Big data cloud accounting platform can optimize the overall budget management process.}

\begin{abstract}
All links of comprehensive budget management of agricultural enterprises can effectively integrate the internal through the cloud platform under the big data. All departments can quickly understand the budget policies and budget objective of enterprises, quickly carry out budget implementation, timely analyze and feedback the differences between budget preparation and implementation subjects, strengthen budget control, and make scientific evaluation on the budget. The application of cloud accounting enables enterprises to input the complete budget process and relevant information data into the cloud central database. The cloud platform processing system examines, analyzes and sorts out the regular process links from a broader perspective and perspective of the company, optimizes and reengineers the budget process in combination with the enterprise strategic planning, and makes the operation process more standardized, efficient and smooth.
\end{abstract}

\subsection{Big data cloud accounting platform can realize rapid transmission of comprehensive budget data.}

Big data deals with the financial data of agricultural enterprises. On the cloud accounting platform, it quickly releases the enterprise budget target for the next year, collects the data of each department to determine the budget formulation policy, revises the budget target, improves the efficiency of budget management, and provides more scientific and comprehensive budget management for agricultural enterprises. 


\subsection{Big data cloud accounting platform reduces the human resource cost of agricultural enterprises.}

Although the cloud accounting platform pays for using, it can greatly reduce the repetitive work. A large number of accounting data are unified through the management and integration of the cloud system, and the database center is unified, which saves the cost of database update, not only speeds up the efficiency of data processing, but also maintains the collaborative control of internal and external information, and improves the comprehensive competitiveness.

\section{Obstacles to the application of cloud accounting in the comprehensive budget management of agricultural enterprises.}

\subsection{Agricultural enterprises have insufficient understanding of the application of cloud accounting platform.}

The managers of agricultural enterprises have doubts about the using effect of big data cloud accounting. Some agricultural enterprises do not know enough about the comprehensive budget management. It is a great challenge to combine the two. In addition, the cost of cloud accounting platform makes the managers of agricultural enterprises look and step back. In the era of big data, information technology has realized information sharing among all departments. Facing the comprehensive data and information, the financial personnel lack of forward-looking thinking and overall view, and the Internet technology is not enough to comprehensively analyze the competition pattern, market trend, business transformation, and comprehensively consider the overall value chain of the enterprise, so the maximization of enterprise value will not be realized.

\subsection{The comprehensive budget management system of agricultural enterprises is not mature.}

Because agricultural enterprises do not pay attention to comprehensive budget management, its comprehensive budget management system, system, process, etc. are not mature, and the responsibilities of personnel are vague. In order to effectively implement the comprehensive budget management of agricultural enterprises, the support of mature and perfect comprehensive budget management system, and the data integration and analysis of efficient big data cloud accounting platform are indispensable.

\subsection{The particularity of agricultural enterprises increases the application of cloud accounting technology.}

Agricultural enterprises take the traditional agricultural economy as the basis, the production cycle of products is longer, and they are more vulnerable to the impact of the natural environment, which makes it more difficult for agricultural enterprises to carry out comprehensive budget At present, the cloud accounting platform has not yet established the database and data management process suitable for the overall budget management of agricultural enterprises, which to some extent hinders the application of cloud accounting in agricultural enterprises.

\section{Measures to accelerate the application of cloud accounting in the comprehensive budget management of agricultural enterprises under big data}

\subsection{Improve the attention of agricultural enterprise managers to cloud accounting.}

Agricultural enterprises have played an important role in the development of agricultural economy. Both the government and the enterprises need to pay more attention to the comprehensive budget management of agricultural enterprises. In addition, they need to keep pace with the times, bravely introduce cloud accounting platform with the help of big data advantages, constantly combine new technology and comprehensive budget management, improve the internal budget management process of agricultural enterprises. The optimization degree of information technology and system directly determines the effect of data transmission, storage and processing. Enterprises also need to strengthen investment in financial information construction, increase efforts in research and development of software programs, upgrading of information systems, system configuration hardware, talent introduction, etc., with the help of modern data systems, intelligent identification and processing, transmission of big data, including semistructured and unstructured data. On the basis of improving the internal control mechanism of the enterprise, we should build a suitable management system, which is mainly responsible for the security of financial information

\subsection{Build a cloud accounting framework for comprehensive budget management of agricultural enterprises.}

The comprehensive budget management system of agricultural enterprises should reflect the characteristics of real-time, sharing and centralization, and need a lot of data collection, storage and analysis. The construction and implementation of comprehensive budget management system has been greatly supported on the basis of big data and cloud accounting platform. Under the framework of enterprise comprehensive budget management system, it is necessary to build the cloud accounting management framework of infrastructure layer, hardware virtualization layer, data layer, platform layer and software layer. With 
the help of cloud accounting platform, budget preparation, budget implementation, budget evaluation and budget supervision are carried out. In the era of big data, cloud accounting will build a relatively perfect data information system and an effective strategic analysis model with the help of cloud accounting platform, so as to effectively optimize the internal control system of the enterprise and achieve the goal of optimizing the budget process of the enterprise.

\subsection{Accelerate the development of cloud accounting platform for comprehensive budget management of agricultural enterprises.}

In the era of big data, cloud accounting has changed the phenomenon of single data information source, established the enterprise budget management data center, effectively integrated the internal and external data of the enterprise, and established the enterprise budget data center, so that the data can provide effective information support for the enterprise development and strategy formulation, and the data information has been transformed from resources to intangible assets of the enterprise. Cloud accounting suppliers should seize the development opportunities, actively communicate with agricultural enterprises, and develop a cloud accounting platform for comprehensive budget management of agricultural enterprises in combination with the particularity of agricultural enterprises. With the advantage of big data, we will increase the comprehensive budget management function, improve the credibility of the cloud accounting platform, improve the data storage capacity and data processing capacity of the cloud accounting platform, and strive to make the cloud accounting platform highly match the overall budget management of agricultural enterprises.

\section{5 conclusion}

In the era of big data, cloud accounting has brought great opportunities for the comprehensive budget management of enterprises, which is of great significance for improving the efficiency of the comprehensive budget management of enterprises. Under the background of big data cloud accounting, the enterprise's comprehensive budget management should further rely on the advantages of cloud accounting, seek an effective way to improve, and constantly optimize the enterprise's comprehensive budget management system to provide strong support for the enterprise's strategic development. Agricultural enterprises need to innovate management concepts, broaden management ideas, accept the changes brought by cloud accounting technology, apply cloud accounting technology to comprehensive budget management, constantly accelerate the realization of accounting information, help agricultural enterprises integrate more financial resources, reduce the cost of business operation, increase business efficiency, adapt to the new normal economic competition situation, and improve their own development competitive advantage.

\section{Acknowledgment}

Project source: 2018 Heilongjiang Provincial Universities Basic Scientific Research Business Expenses Scientific Research Project, No.2018-KYYWF-014

\section{References}

1. $\mathrm{Xu}$ Qunying, "Thoughts on the Problems in the Application of Cloud Accounting Practice" Proceedings of 2019 International Conference on Arts,Management,Education and Innovation(ICAMEI 2019), pp. 129-132,April 2019

2. Cheng Ping, "Comprehensive budget management of group enterprises based on cloud accounting in the era of big data", Friends of Accounting, 2015 (18)

3. Song Zhiqing, "My opinion on the informatization of comprehensive budget management under the background of big data" ,Market Modernization, 2019 (22)

4. Xia Xinrui, "Development strategy of comprehensive budget management in accounting information environment",Business Manager, 2019 (09)

5. Cai Yuna, "On the information application and problems of comprehensive budget management" ,Modern Economic Information,2019 (16) 